\title{
Hyperferritinemia in children hospitalized with scrub typhus
}

\author{
Vijai Williams ${ }^{1}$, Nisha Menon ${ }^{1}$, Prateek Bhatia ${ }^{2}$, Manisha Biswal ${ }^{3}$, Sreejesh Sreedharanunni ${ }^{4}$, \\ Muralidharan Jayashree ${ }^{1}$ (D) and Karthi Nallasamy ${ }^{1 *}$ (D)
}

\begin{abstract}
Background: Hyperferritinemia is increasingly associated with mortality in sepsis. Studies estimating the prevalence of hyperferritinemia in pediatric scrub typhus are limited.

Methods: This was a secondary analysis of a prospective observational study (FERRIS) from a tertiary care teaching hospital in North India where 72 children with confirmed scrub typhus, 4 (5.5\%) PCR positive, 55 (76.4\%)-IgM ELISA positive, and 13 (18.1\%)-both PCR and ELISA positive, were analyzed. Serum ferritin was measured in 62 children to identify the prevalence of hyperferritinemia and determine its association with mortality.

Results: Hyperferritinemia (> $500 \mu \mathrm{g} / \mathrm{L}$ ) was seen in 72.6\% $[n=45]$ children; $26(41.9 \%)$ were mild $(500-2000 \mu \mathrm{g} / \mathrm{L})$, $13(21 \%)$ were moderate $(2000-10,000 \mu \mathrm{g} / \mathrm{L})$, and $6(9.7 \%)$ were severe $(>10,000 \mu \mathrm{g} / \mathrm{L})$. Early presentation to hospital ( $\leq 7$ days of febrile illness) had more survivors than late presentation ( $>7$ days). Non-survivors had significantly higher PRISM III, PELOD-2, hyperlactatemia, hypoalbuminemia, organ dysfunction, need for mechanical ventilation, and need of RRT. Ferritin had poor sensitivity and specificity in predicting survival with AUC of 0.56. Organ dysfunction and risk scores as PRISM III, PELOD 2, and VIS at admission were better predictors with AUC (95\% CI) of $0.72(0.56,0.89), 0.77(0.63,0.92)$, and $0.90(0.78,1.0)$ respectively.
\end{abstract}

Conclusions: Hyperferritinemia is common in scrub typhus but it did not predict survival. Organ dysfunction and risk scores were better predictors of mortality than ferritin.

Keywords: Pediatric, Ferritin, Scrub typhus, Mortality, Sepsis

\section{Background}

Scrub typhus is a common cause of acute undifferentiated fever in Asian countries [1]. The disease manifests with protean clinical features varying from undifferentiated fever to several organ dysfunctions that include acute respiratory distress syndrome (ARDS), myocarditis, acute kidney injury (AKI), encephalitis, acute liver failure, and culminating in multiorgan dysfunction syndrome (MODS) [2, 3]. Early suspicion and treatment are essential as delay increases morbidity and mortality multifold. A significant overlap of symptoms with other

\footnotetext{
* Correspondence: ny.karthi@gmail.com

'Division of Pediatric Emergency and Intensive care, Department of Pediatrics, Advanced Pediatrics Centre, Postgraduate Institute of Medical Education \& Research, Sector-12, Chandigarh 160012, India

Full list of author information is available at the end of the article
}

viral and certain bacterial sepsis makes the diagnosis difficult, and hence, a syndromic approach is recommended [4]. The pathogenesis differs from other bacterial causes of sepsis in early and severe involvement of vascular endothelium [5]. Hematological dysfunction is prominent; most present with thrombocytopenia as a prominent feature with varying degrees of anemia [6]. Other organ dysfunctions are not uncommon, and they have an additive association with mortality [7-9].

Several clinical and laboratory parameters showed inconsistent results in predicting organ dysfunction and survival in pediatric scrub typhus [9-11]. Ferritin can be an attractive marker as hematological dysfunction is prominent in these children especially in those with MODS [12]. From a mere marker of iron stores, the role of ferritin in disease pathogenesis and immunomodulation is increasingly being

(c) The Author(s). 2021 Open Access This article is licensed under a Creative Commons Attribution 4.0 International License, which permits use, sharing, adaptation, distribution and reproduction in any medium or format, as long as you give appropriate credit to the original author(s) and the source, provide a link to the Creative Commons licence, and indicate if changes were made. The images or other third party material in this article are included in the article's Creative Commons licence, unless indicated otherwise in a credit line to the material. If material is not included in the article's Creative Commons licence and your intended use is not permitted by statutory regulation or exceeds the permitted use, you will need to obtain permission directly from the copyright holder. To view a copy of this licence, visit http://creativecommons.org/licenses/by/4.0/. 
explored in sepsis [12-14]. Hyperferritinemic syndrome seen in critically ill children is attributed secondary to hypercytokinemia and macrophage activation, both wellknown in scrub typhus [15]. However, robust studies on ferritin measurements in this cohort are lacking.

We hypothesized that early elevated ferritin may help identify the severe cases of scrub typhus that progress to MODS and eventual death. Hence, we planned this observational study to measure serum ferritin in children with confirmed scrub typhus and determine its association with disease severity and outcome.

\section{Methods}

This was a secondary analysis of the ferritin in sepsis (FERRIS) study [16] which was a single center, prospective study at a tertiary care teaching hospital in North India. Children aged between 1 month and 12 years admitted to Pediatric Emergency Department and Pediatric Intensive Care Unit (PICU) of the Advanced Pediatrics Center, Postgraduate Institute of Medical Education and Research, were consecutively enrolled from July 2019 to December 2019 (6 months), the season with peak incidence of tropical infections. We chose this age cutoff as the upper age limit for pediatric admission is 12 years as per hospital policy.

Children with acute febrile illness (fever $>38.3{ }^{\circ} \mathrm{C}$ for more than $48 \mathrm{~h}$ duration and onset $<14$ days) with either (a) cytopenia (platelet count $<100,000 / \mathrm{mm}^{3}$, and/or hemoglobin $<10 \mathrm{~g} / \mathrm{dl}$ ), (b) organomegaly (hepatomegaly/splenomegaly), (c) lymphadenopathy, or (d) systemic signs (rash, edema) were screened for eligibility and included if they were confirmed scrub typhus either by PCR or IgM ELISA. Children who received a transfusion were excluded. Less severe illness with presentation as undifferentiated fever without organ dysfunction and those who did not require hospitalization were not included in this study.

Children who met the eligibility criteria were enrolled consecutively after obtaining a written informed consent. Demographic, clinical, and laboratory data were collected. Complete blood counts and renal and liver function tests were performed at presentation for all cases and were repeated if necessary. Acute kidney injury was staged as per KDIGO guidelines [17]. Treatment-related variables, severity score (PRISM III, PELOD2), details of organ supportive therapies, length of PICU stay, and hospital outcome were recorded.

Diagnosis of scrub typhus was confirmed by PCR and/ or IgM ELISA. Nested PCR was performed using the DNA extracted from the whole blood and was amplified to detect Orientia tsutsugamushi DNA. We used the oligonucleotide primers that were based on the nucleotide sequences of a gene encoding for the $56-\mathrm{kDa}$ antigen of a Gilliam strain of Orientia tsutsugamushi. ELISA for scrub typhus IgM antibody was performed using Scrub Typhus Detect IgM ELISA (InBios International Inc., Seattle, WA). An optical density of $\geq 0.5$ was considered as diagnostic for scrub typhus. All children underwent blood culture, Dengue IgM ELISA, NS1 antigen ELISA, IgM for leptospirosis, blood smears for malaria, Widal test, and serology for hepatitis A and E to rule out other seasonal infections.

Serum ferritin was estimated from the 2-3 ml EDTA blood sample collected at admission. Plasma was separated after centrifugation at $3000 \mathrm{rpm}$ for $15 \mathrm{~min}$ and stored at $-80{ }^{\circ} \mathrm{C}$. Samples were processed in batches of 10-15 samples every week using the chemiluminescence principle on the ADVIA Centaur Ferritin System (Siemens Healthcare Diagnostics, Los Angeles, CA) as per manufacturer's instructions. If clinical suspicion of hemophagocytic lymphohistiocytosis (HLH) (persistence of fever, worsening cytopenia, and organ dysfunction) and/or elevated serum ferritin $\geq 2000 \mu \mathrm{g} / \mathrm{L}$, then other relevant tests such as triglycerides, fibrinogen, and/or bone marrow examination were performed as per clinician's decision. Decision to treat HLH with immunomodulatory therapy (steroids, IvIg, or both) was at the treating clinician's discretion. The study protocol was approved by the Institute Ethics Committee.

\section{Definitions}

Hyperferritinemia was defined as ferritin levels more than $500 \mu \mathrm{g} / \mathrm{L}[12,15,18]$. We stratified hyperferritinemia into mild (500-2000), moderate (>2000-10,000), and severe $(>10,000)$ categories. We classified the subjects into early presenters ( $\leq 7$ days of febrile illness) and late presenters ( $>7$ days of febrile illness) to see if day of presentation since fever onset affected degree of hyperferritinemia. Organ dysfunction was defined as per Pediatric Logistic Organ Dysfunction score (PELOD-2) [19]. PELOD-2 was done daily till 5 days or till discharge which ever was earlier. The vasoactive drugs used during therapy were monitored and daily vasoactive inotrope score (VIS) was calculated [20].

\section{Outcome}

The primary outcome was to identify the prevalence of hyperferritinemia in hospitalized children with scrub typhus. The secondary outcomes were to study the predictors of mortality in scrub typhus and determine the association of serum ferritin levels with duration of illness and mortality.

\section{Statistical analysis}

Descriptive statistics including frequency, mean, median, interquartile range (IQR), and standard deviation (SD) were calculated for the demographic data and laboratory parameters. The prevalence of hyperferritinemia $(>500$ 
$\mathrm{ng} / \mathrm{ml}$ ) reported from previous studies was $25-55 \%$ [13, 15]. Hence, we estimated sample size as 70 based on the assumed prevalence estimate of $25 \%$, with a precision of $10 \%$ and $95 \%$ confidence interval (CI). Comparison of characteristics between survivors and nonsurvivors was made with Chi-square test for categorical data and the Mann-Whitney test for continuous nonparametric data. Predictors of mortality were identified using binary logistic regression. The sensitivity and specificity for different cutoff values of ferritin were analyzed using a receiver operating characteristic (ROC) curve and were compared with organ dysfunction and risk scores. For all tests, a two-sided $P$ value of $<0.05$ was considered statistically significant. All statistical analyses were performed using the SPSS software version 23.0 (SPSS Inc., Chicago, IL).

\section{Results}

\section{Baseline characteristics}

During the 6 months of study period, 10,158 children visited Pediatric Emergency Department and 4130 of them required admission. A total of 242 children were eligible, and only 72 children met the inclusion criteria (Fig. 1). Of them, 4 were (5.5\%) PCR positive, 55

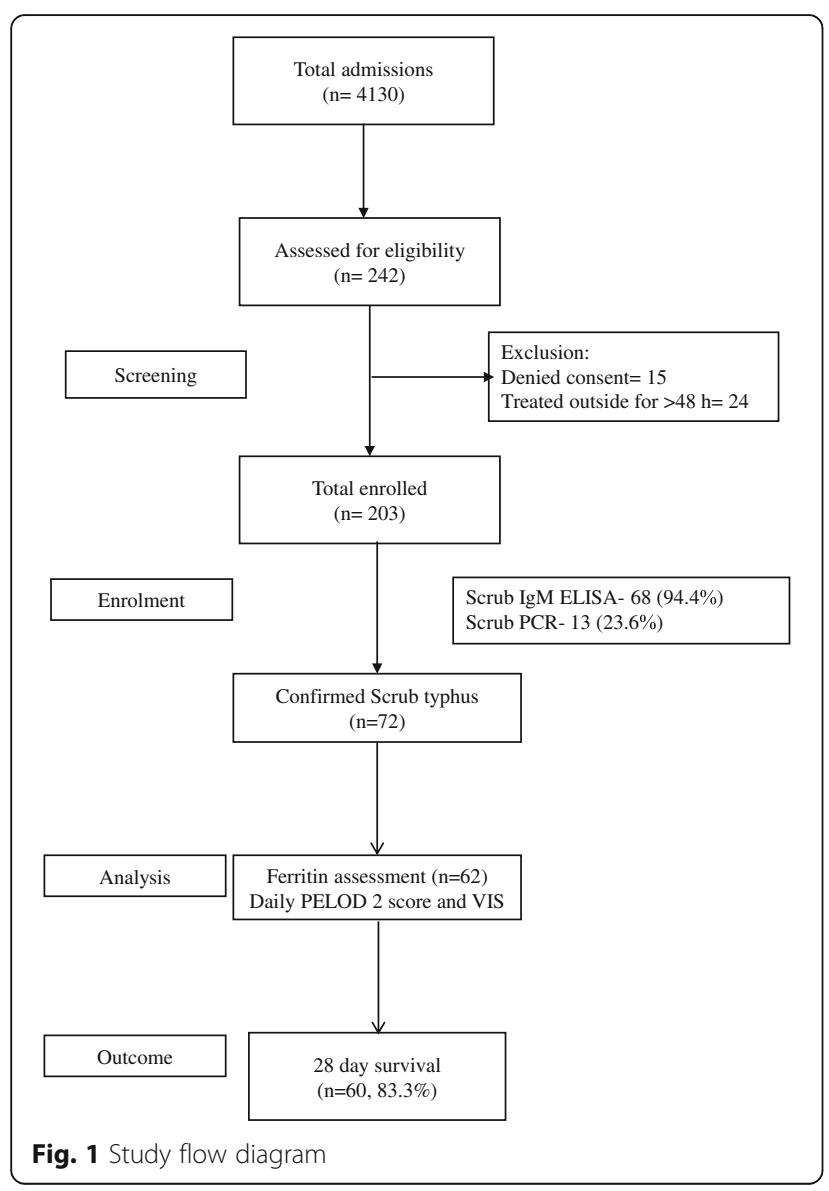

(76.4\%)-IgM ELISA positive, and 13 (18.1\%)-both PCR and ELISA positive. The median (IQR) age of presentation was $60(36,96)$ months with a male preponderance ( $n=45,62.5 \%$ ) (Table 1$)$. The median (IQR) PRISM III and PELOD 2 score at admission were $8(5,12)$ and 3 $(2,7)$ respectively. Fever was present in all; generalized edema, fast breathing, and abdominal pain were other

Table 1 Clinical profile, investigations, and outcomes

\begin{tabular}{|c|c|}
\hline Parameter & $N=72$ \\
\hline Age in months & $60(36,96)$ \\
\hline Boys, $n(\%)$ & $45(62.5)$ \\
\hline Weight in kg & $16.0(11.4,20.75)$ \\
\hline Weight in $Z$ score & $-1.37(-2.18,-0.24)$ \\
\hline PRISM III & $8(5,12)$ \\
\hline Duration of illness in days & $7(5,10)$ \\
\hline \multicolumn{2}{|l|}{ Clinical features } \\
\hline Fever, $n(\%)$ & $72(100)$ \\
\hline Edema, $n(\%)$ & $35(48.6)$ \\
\hline Fast breathing, $n(\%)$ & $27(37.5)$ \\
\hline Abdominal pain, $n(\%)$ & $25(34.7)$ \\
\hline Bleeding manifestations, $n(\%)$ & $17(23.6)$ \\
\hline Altered sensorium, $n$ (\%) & $16(22.2)$ \\
\hline Seizures, $n(\%)$ & $16(22.2)$ \\
\hline Headache, $n$ (\%) & $14(19.4)$ \\
\hline Purpuric rash, $n$ (\%) & $8(11.1)$ \\
\hline Oliguria, $n(\%)$ & $6(8.3)$ \\
\hline Hepatomegaly, n (\%) & $66(91.7)$ \\
\hline Splenomegaly, n (\%) & $43(59.7)$ \\
\hline Eschar, n (\%) & $14(19.4)$ \\
\hline \multicolumn{2}{|l|}{ Investigations } \\
\hline Hemoglobin, g/dl & $8.7(7.4,10.2)$ \\
\hline Platelet count, cells $/ \mathrm{mm}^{3}$ & $44,000(18,000,80,000)$ \\
\hline Total bilirubin, mg/dl & $0.8(0.6,1.9)$ \\
\hline Aspartate transaminase, $\mathrm{U} / \mathrm{L}$ & $185(94,285)$ \\
\hline Alanine transaminase, $\mathrm{U} / \mathrm{L}$ & $79(49,125)$ \\
\hline International normalized ratio & $1.2(1.0,1.5)$ \\
\hline \multicolumn{2}{|l|}{ Treatment } \\
\hline Doxycycline, $n(\%)$ & $65(90.3)$ \\
\hline Azithromycin, $n$ (\%) & $7(9.7)$ \\
\hline Ivlg only, $n(\%)$ & $2(2.8)$ \\
\hline Ivlg with steroid, $n(\%)$ & $2(2.8)$ \\
\hline \multicolumn{2}{|l|}{ Outcome } \\
\hline Survivors, $n$ (\%) & $60(83.3)$ \\
\hline Length of PICU stay, days & $5(4,9)$ \\
\hline Length of hospital stay, days & $5(3,8)$ \\
\hline
\end{tabular}

All values expressed as median (IQR) PRISM Pediatric Risk of Mortality 
common symptoms. Hepatomegaly was seen in 66 (91.7\%) and splenomegaly in 43 (59.7\%) children. Eschar, a pathognomonic clue to trombiculid bite, was seen only in $14(19.4 \%)$ children. A rash was noted in $11 \%$ patients which varied from macular, blanching erythematous rash to petechial purpuric lesions.

The median (IQR) hemoglobin was $8.7(7.4,10.2) \mathrm{g} / \mathrm{dL}$ (Table 2). The median (IQR) platelet count was 44,000 $(18,000,80,000)$ cells $/ \mathrm{mm}^{3}$. Severe hypoalbuminemia was common; more than half had serum albumin $<2.5$ $\mathrm{g} / \mathrm{dL}$ at admission. Elevated liver enzymes $(>5$ times elevation of AST/ ALT) were seen in 27 of 65 children (41.5\%).

\section{Clinical course}

A total of 36 (50\%) children required PICU admission. Hematological dysfunction was the commonest organ dysfunction $[n=68,94.4 \%]$. Respiratory failure $[n=40$, $56 \%]$ was the next common organ dysfunction; acute respiratory distress syndrome (ARDS) was seen in 31.9\% children. Nearly half $(n=34,47 \%)$ received mechanical ventilation. Twenty children (28.2\%) had shock requiring

Table 2 Comparison of baseline characteristics among survivors and nonsurvivors

\begin{tabular}{|c|c|c|c|c|c|}
\hline & $N$ & Total $(n=72)$ & Survivors $(n=60)$ & Nonsurvivors $(n=12)$ & $P$ value \\
\hline \multicolumn{6}{|l|}{ Parameter } \\
\hline Age, months & 72 & $60(36,96)$ & $60(30,98)$ & $36(31,105)$ & 0.60 \\
\hline Boys, $n(\%)$ & 72 & $45(62.5)$ & $41(68.3)$ & $4(33.3)$ & 0.04 \\
\hline PRISM III & 72 & $8(5,12)$ & $8(5,11)$ & $12(8.7,17.5)$ & 0.005 \\
\hline Duration of illness, days & 72 & $7(5,10)$ & $7(5,9.5)$ & $9(5,12)$ & 0.38 \\
\hline \multicolumn{6}{|l|}{ Investigations } \\
\hline Ferritin, $\mu \mathrm{g} / \mathrm{L}$ & 62 & $668(420,2714)$ & $666(382,2653)$ & $1806(443,4727)$ & 0.53 \\
\hline Normal (<500), n (\%) & & $17(27.4)$ & $15(28.8)$ & $2(20)$ & 0.42 \\
\hline Mild (> 500-2000), n (\%) & & $26(41.9)$ & $23(44.2)$ & $3(30)$ & \\
\hline Moderate (> 2000-10,000), n (\%) & & $13(21)$ & $10(19.2)$ & $3(30)$ & \\
\hline Severe $(>10,000), n(\%)$ & & $6(9.7)$ & $4(7.8)$ & $2(20)$ & \\
\hline Hemoglobin, g/dl & 72 & $8.7(7.4,10.2)$ & $8.6(7.5,10.5)$ & $8.1(6.8,10.1)$ & 0.48 \\
\hline Total leukocyte count cells $/ \mathrm{mm}^{3}$ & 72 & $14,000(9820,18,000)$ & $14,090(10,200,17,500)$ & $12465(7020,21,080)$ & 0.39 \\
\hline Platelet count cells $/ \mathrm{mm}^{3}$ & 72 & $18,000(44,000,80,000)$ & $19,000(48,000,80,000)$ & $31000(11,500,100,000)$ & 0.39 \\
\hline Albumin, g/dl & 58 & $2.2(2.1,2.6)$ & $2.3(2.1,2.6)$ & $2.1(1.9,2.2)$ & 0.05 \\
\hline Severe hypoalbuminemia (<2.5 g/dl), $n$ (\%) & 58 & $39(54.2)$ & $30(50)$ & $9(75)$ & 0.14 \\
\hline Lactate, $\mathrm{mmol} / \mathrm{L}$ & 72 & $1.6(1.1,2.6)$ & $1.6(1,1.8)$ & $3.0(1.85,9.8)$ & 0.04 \\
\hline \multicolumn{6}{|l|}{ Organ dysfunction } \\
\hline Hematological dysfunction, $n(\%)$ & 72 & $68(94.4)$ & $56(93.3)$ & $12(100)$ & 0.60 \\
\hline Respiratory failure, $n(\%)$ & 72 & $40(55.5)$ & $28(46.6)$ & $12(100)$ & 0.001 \\
\hline ARDS, $n(\%)$ & 72 & $23(31.9)$ & $13(21.7)$ & $10(83.3)$ & $<0.0001$ \\
\hline Mechanical ventilation, $n(\%)$ & 72 & $34(47.2)$ & $22(36.7)$ & $12(100)$ & 0.0001 \\
\hline Shock, $n(\%)$ & 72 & $20(28.2)$ & $12(20.3)$ & $8(66.7)$ & 0.003 \\
\hline VIS on day 1 & 72 & $0(0,10)$ & $0(0,0)$ & $10(0,30)$ & 0.0001 \\
\hline $\mathrm{AKI}, n(\%)$ & 72 & 15 (20.8) & $10(16.7)$ & $5(41.7)$ & 0.02 \\
\hline RRT, $n(\%)$ & 72 & $5(6.9)$ & $2(3.3)$ & $3(25)$ & 0.03 \\
\hline CNS dysfunction, $n$ (\%) & 72 & $10(13.9)$ & $6(10)$ & $4(33.3)$ & 0.05 \\
\hline Coagulopathy (INR > 1.5), n (\%) & 56 & $12(21.4)$ & $10(21.3)$ & $2(22.2)$ & 1.0 \\
\hline \multicolumn{6}{|l|}{ PELOD-2 score } \\
\hline Day 1 & 72 & $3(2,7)$ & $2(2,5)$ & $7(7,9)$ & $<0.0001$ \\
\hline Day 2 & 67 & $2(1,5)$ & $2(1,5)$ & $6(4,7)$ & 0.001 \\
\hline Day 3 & 64 & $2(1,5)$ & $2(1,4)$ & $4(1,6)$ & 0.32 \\
\hline
\end{tabular}

All values expressed as median (IQR) PRISM Pediatric Risk of Mortality, PELOD Pediatric Logistic Organ Dysfunction, ARDS Acute Respiratory distress syndrome, VIS vasoactive inotrope score, AKI acute kidney injury, $R R T$ renal replacement therapy 
vasoactive drug support. AKI was seen in 15 (20.8\%) children, and 5 (7\%) required RRT. Encephalopathy with GCS $<10$ was seen in $10(13.9 \%)$ children. Sixty-five children were treated with doxycycline, and 7 received azithromycin. The median (IQR) length of hospital stay was $5(3,8)$ days. Sixty children survived to hospital discharge, and all $[n=60,83.3 \%]$ were alive at 28-day follow-up. Four children (5.5\%) had clinical features and investigations that fulfilled HLH diagnostic criteria. All 4 received intravenous immunoglobulin (IvIg), and 2 of them were also treated with methylprednisolone. Of them, 2 survived and 2 died.

\section{Hyperferritinemia}

Ferritin estimation was possible in 62 children. Ferritin measurement of 10 samples was disregarded owing to inadequate or improper sample and hemolysis during storage. The median (IQR) day of ferritin measurement since symptom onset was $7(5,10)$ days. The median (IQR) ferritin level was $668(42,2714) \mu \mathrm{g} / \mathrm{L}$. Seventeen children $(27.4 \%)$ had ferritin in normal range. Hyperferritinemia $(>500 \mu \mathrm{g} / \mathrm{L})$ was seen in $45(72.6 \%)$ children; $26(41.9 \%)$ were mild, 13 (21\%) were moderate, and 6 (9.7\%) were severe. Ferritin levels were not significantly different between survivors and nonsurvivors $(p=0.53)$.

Among early presenters, 25 children had hyperferritinemia of whom 22 (88\%) survived. Of late presenters, 20 children had hyperferritinemia and 15 (75\%) survived. This difference did not reach statistical significance $[p=$ 0.2 , OR $(95 \%) 2.4(0.5,11.4)]$. The difference in ferritin levels between survivors and nonsurvivors at these two timelines was also not significant (Fig. 2).

\section{Predictors of outcome}

Although nonsurvivors had significantly higher PRISM III, PELOD-2, hyperlactatemia, hypoalbuminemia, organ

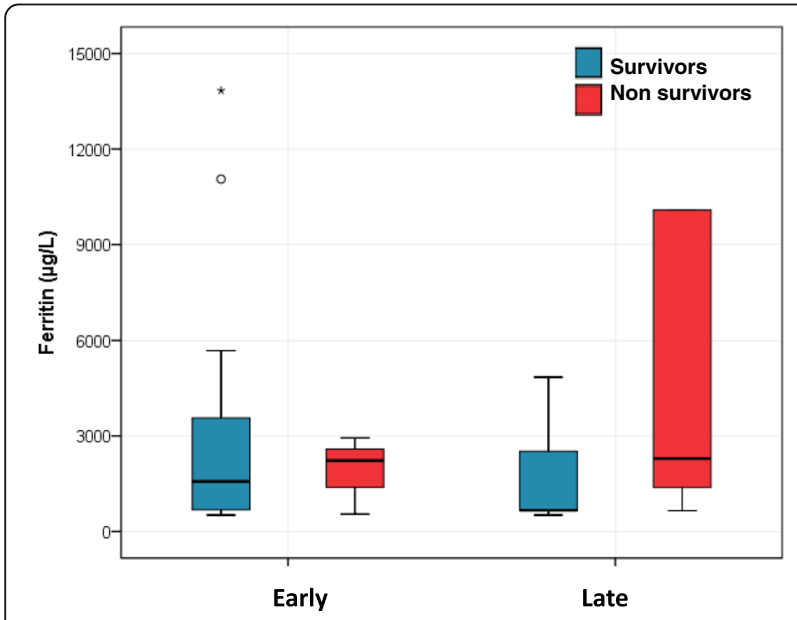

Fig. 2 Boxplot showing differences in median ferritin value between early and late presentation dysfunction, need for mechanical ventilation, and need of RRT, on binary logistic regression analysis, none of them was shown to predict mortality. Ferritin was higher in nonsurvivors $[1806(443,4727) \mu \mathrm{g} / \mathrm{L}]$ than survivors [666 $(382,2653) \mu \mathrm{g} / \mathrm{L}]$, but the difference was statistically not significant. We found that ferritin has poor sensitivity and specificity in predicting mortality with AUC (95\% CI) of $0.56(0.35,0.78)$ (Fig. 3). It was observed that higher ferritin values increased specificity to predict mortality. Ferritin value above $496 \mu \mathrm{g} / \mathrm{L}$ had $80 \%$ sensitivity and $29 \%$ specificity, and value above $2000 \mu \mathrm{g} /$ L had $50 \%$ sensitivity and $73 \%$ specificity while value above $7880 \mu \mathrm{g} / \mathrm{L}$ had $20 \%$ sensitivity and $93 \%$ specificity. We found that organ dysfunction and risk score as PRIS M III, PELOD 2, and VIS at admission were better predictors with AUC $(95 \% \mathrm{CI})$ of $0.72(0.56,0.89), 0.77$ $(0.63,0.92)$, and $0.90(0.78,1.0)$ respectively. VIS score > 16.5 was $80 \%$ sensitive and $88 \%$ specific to predict mortality. A PELOD-2 score $>7$ had $80 \%$ sensitivity and $91 \%$ specificity while a PRISM III score $>10$ had $70 \%$ sensitivity and $71 \%$ specificity in predicting mortality.

\section{Discussion}

In this prospective study, we found that hyperferritinemia is common in scrub typhus and about a third (30.7\%) had ferritin values more than $2000 \mu \mathrm{g} / \mathrm{L}$. Severe hyperferritinemia $(>10,000 \mu \mathrm{g} / \mathrm{L})$ was seen in $10 \%$. Ferritin did not have good predictive ability for outcome though the nonsurvivors had higher proportion of moderate and severe hyperferritinemia than survivors. PELOD-2 and VIS score fared better than ferritin in predicting mortality. The reported case fatality rate in scrub typhus varies between 1.5 and $30 \%$ with a median of about $8 \%[2,21]$. The case fatality rate in this study is

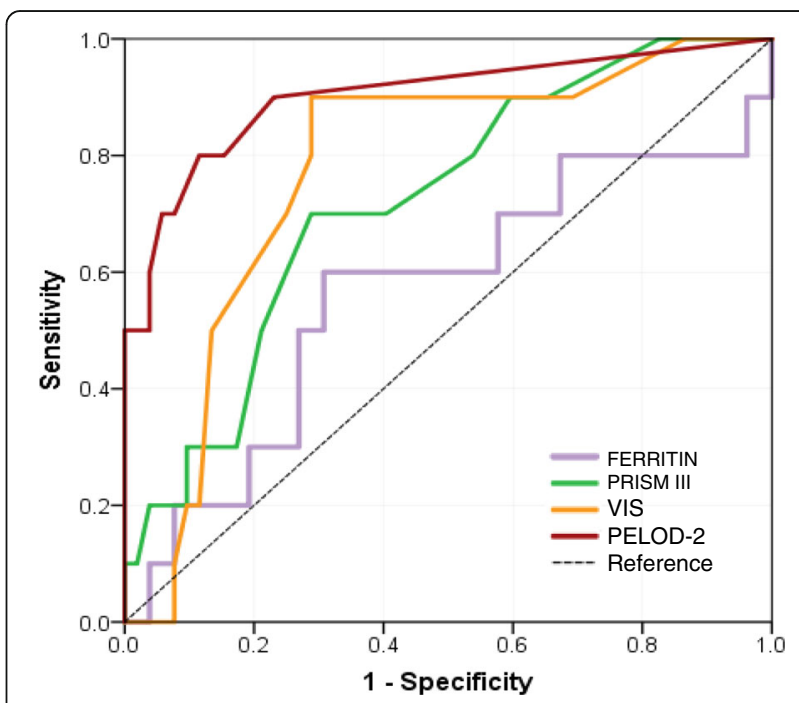

Fig. 3 Receiver operating characteristic curve comparing ferritin, PELOD 2 score, and VIS for predicting mortality 
higher (16.7\%). This may be due to the referral bias and the inclusion criteria selecting cases with high severity of illness as evidenced by a higher PRISM III and PELOD-2 scores at admission.

Organ dysfunction is common in scrub typhus. The mortality is proportionate to the severity and number of organ systems involved [8]. An elevated SOFA score has been independently associated with mortality in adult studies [8]. In our cohort, the median (IQR) PELOD2 scores at admission was $2(2,5)$ among survivors as compared to $7(7,9)$ in nonsurvivors.

Ferritin is being used as a marker to determine the body iron stores since 1970s [22]. Ever since, the focus on ferritin has diversified with its role in inflammation, infection, and malignancy. Surprisingly, our understanding on its mechanisms in different diseases is still enigmatic despite 5 decades of clinical research. Despite the mention in 2004 HLH criteria, elevation of ferritin greater than $500 \mu \mathrm{g} / \mathrm{L}$ could still be nonspecific in infections. In our study too, hyperferritinemia was seen in $72.6 \%$, reiterating its function as an acute phase reactant to infection. More than half had mild elevation, but severe hyperferritinemia was seen only in $10 \%$ of children. Be it changing epidemiology or increased recognition, hyperferritinemia as a syndrome is increasingly diagnosed in critically ill children [23]. The pathogenesis of hyperferritinemia in sepsis/systemic inflammation continues to evolve in recent literature [24]. With growing evidence, ferritin is now believed to play a key role in normal host response to infection and immunomodulation rather than a nonspecific marker with sole function of sequestrating iron from the circulation $[25,26]$.

Illness-appropriate response in ferritin is believed to correlate with favorable outcome. Both high and very low responses were shown to be associated with increased mortality in patients with sepsis. Garcia et al. observed a mortality of $23 \%$ and $58 \%$ when ferritin values were $<200 \mu \mathrm{g} / \mathrm{L}$ and $>500 \mu \mathrm{g} / \mathrm{L}$ respectively. However, patients with ferritin between 200 and 500 had only $9 \%$ mortality [13]. Bennett et al. observed a stepwise increase in mortality risk in hospitalized children with ferritin $\geq 1000 \mu \mathrm{g} / \mathrm{L}$ and $\geq 3000 \mu \mathrm{g} / \mathrm{L}$ [27].

It has been highlighted that iron may not serve as an essential nutrient for intracellular obligate bacteria like Chlamydia and Rickettsial species. These organisms tend to grow in an iron-deficient media to avoid excessive free iron stress and also do not have functional homology sequences to siderophore synthesis enzymes in their genomes [28, 29]. Ellison et al. in their experimental study supported this hypothesis that there is minimal transcriptional response after iron depletion in rickettsial culture exposed to iron chelator $24 \mathrm{~h}$ after in vitro treatment [30]. Moreover, it is observed that Orientia tsutsugamushi infect human monocytic cells and increases expression of interferon type-1 genes resulting in a M1 type of monocyte-macrophage phenotype which sequesters iron within macrophages [31].

With this knowledge, it is likely that in individuals who have relatively normal iron stores, rickettsial infection would trigger the M1 macrophage phenotype response resulting in transient early hyperferritinemia due to macrophage sequestration of iron and increased transcription of ferritin gene as acute phase reactant. This response also leads to better interferon and pro-inflammatory cytokine secretion by macrophage resulting in better control of infection and a favorable outcome. However, those with low or absent stores can have a delayed elevation of ferritin. This when compounded by multiple other host factors such as secondary macrophage activation and organ dysfunction in late presenters could explain the high mortality in this subgroup. Also, it is logical to appreciate that the higher mortality is strongly linked to the delay in receiving specific antimicrobial therapy in the late presenters.

Four children (5.5\%) were treated for secondary HLH, of whom 2 survived. Diagnosis of HLH is often challenging in scrub typhus as children would present with fever, cytopenia and organomegaly at the outset. Ferritin elevation $>500 \mu \mathrm{g} / \mathrm{L}$ can be very nonspecific as seen in our cohort. Secondary HLH may not require aggressive management when compared to primary HLH. Demirkol et al. showed $100 \%$ survival in children with hyperferritinemic sepsis MODS/MAS/HLH who were treated with methylprednisolone, IVIG, and plasma exchange, whereas those treated with the HLH-94 protocol using chemotherapy and dexamethasone had only $50 \%$ survival as all deaths occurred from overwhelming sepsis [15]. Our cohort received IvIg as first line; steroids were added in 2 children.

Our study has some important strengths. This is one of the largest prospective pediatric studies on scrub typhus evaluating the prevalence of hyperferritinemia. We included children with laboratory-confirmed scrub typhus and followed them up till 28 days with daily evaluation of organ dysfunction. However, a few limitations need mention. Our cohort had greater proportion of severe scrub typhus cases which could have led to increase in the prevalence of hyperferritinemia. The possibility of selection bias due to the stringent inclusion criteria that included features of organ dysfunction to increase the specificity of the diagnosis could not be negated. Children presented to emergency short stay area with less severe disease were not included that could potentially have overestimated the prevalence of hyperferritinemia. Majority of the patients were only IgM positive but PCR negative. The seasonal presentation, suggestive 
clinical syndrome along with IgM positivity, adds weight to the diagnosis of scrub typhus although it is not confirmatory. Serial ferritin measurements and its trend with respect to clinical course and treatment may give more answers regarding the pathogenesis.

\section{Conclusions}

Hyperferritinemia is common in scrub typhus but it did not predict clinical outcomes. Organ dysfunction scores were found to be better predictors of mortality than ferritin.

\section{Abbreviations}

AKI: Acute kidney injury; ARDS: Acute respiratory distress syndrome; DIC: Disseminated intravascular coagulation; ELISA: Enzyme-linked immunosorbent assay; Ivlg: Intravenous immunoglobulin; KDIGO: Kidney Diseases Improving Global Outcomes; MODS: Multiorgan dysfunction syndrome; PCR: Polymerase chain reaction; PELOD: Pediatric Logistic Organ Dysfunction; PICU: Pediatric intensive care unit; PRISM: Pediatric risk of mortality; VIS: Vasoactive inotrope score

\section{Acknowledgements}

Not applicable

\section{Authors' contributions}

KN had full access to all the data in the study and took responsibility for the integrity of the data and the accuracy of the data analysis. All authors participated in the study concept and design. WW and NM had collected, analyzed, and interpreted study data. W, NM, and KN drafted the manuscript. PB helped in ferritin estimation. MB helped in laboratory confirmation of scrub typhus through PCR and ELISA. SS did bone marrow examination in those suspected with HLH. JM and SS gave critical inputs during revision of the manuscript. JM and KN provided administrative, technical, or material support. All authors read and approved the final manuscript.

\section{Funding}

None

\section{Availability of data and materials}

The datasets used and/or analyzed during the current study are available from the corresponding author on reasonable request.

\section{Ethics approval and consent to participate}

Trial was initiated after approval from the Institute Ethics Committee, Postgraduate Institute of Medical Education \& Research, Chandigarh, India (NK/5433/Study/594). A written informed consent was obtained from a parent or guardian for all participants.

\section{Consent for publication}

Not applicable

\section{Competing interests}

The authors declare no competing interests.

\section{Author details}

'Division of Pediatric Emergency and Intensive care, Department of Pediatrics, Advanced Pediatrics Centre, Postgraduate Institute of Medical Education \& Research, Sector-12, Chandigarh 160012, India. ${ }^{2}$ Division of Pediatric Hematology, Department of Pediatrics, Advanced Pediatrics Centre, Postgraduate Institute of Medical Education \& Research, Chandigarh, India. ${ }^{3}$ Department of Medical Microbiology, Postgraduate Institute of Medical Education \& Research, Chandigarh, India. ${ }^{4}$ Department of Hematology, Postgraduate Institute of Medical Education \& Research, Chandigarh, India.
Received: 6 October 2020 Accepted: 1 February 2021

Published online: 17 February 2021

\section{References}

1. Chrispal A, Boorugu H, Gopinath KG, Chandy S, Prakash JAJ, Thomas EM et al. Acute undifferentiated febrile illness in adult hospitalized patients: the disease spectrum and diagnostic predictors - an experience from a tertiary care hospital in South India. Trop Doct. 2010;40:230-4.

2. Nallasamy K, Gupta S, Bansal A, Biswal M, Jayashree M, Zaman K, et al. Clinical profile and predictors of intensive care unit admission in pediatric scrub typhus: a retrospective observational study from North India. Indian J Crit Care Med. 2020;24:445-50.

3. Singhi S, Rungta N, Nallasamy K, Bhalla A, Peter JV, Chaudhary D, et al. Tropical fevers in Indian intensive care units: a prospective multicenter study. Indian J Crit Care Med Peer-Rev Off Publ Indian Soc Crit Care Med. 2017:21:811-8

4. From: The Indian Society of Critical Care Medicine Tropical fever Group, Singhi S, Chaudhary D, Varghese GM, Bhalla A, Karthi N, et al. Tropical fevers: management guidelines. Indian J Crit Care Med Peer-Rev Off Publ Indian Soc Crit Care Med. 2014:18:62-9.

5. Valbuena $\mathrm{G}$, Walker $\mathrm{DH}$. Infection of the endothelium by members of the order Rickettsiales. Thromb Haemost. 2009;102:1071-9.

6. Lee H-J, Park C-Y, Park S-G, Yoon N-R, Kim D-M, Chung C-H. Activation of the coagulation cascade in patients with scrub typhus. Diagn Microbiol Infect Dis. 2017;89:1-6.

7. Taylor AJ, Paris DH, Newton PN. A systematic review of mortality from untreated scrub typhus (Orientia tsutsugamushi). PLoS Negl Trop Dis. 2015;9: e0003971.

8. Griffith M, Peter JV, Karthik G, Ramakrishna K, Prakash JAJ, Kalki RC, et al. Profile of organ dysfunction and predictors of mortality in severe scrub typhus infection requiring intensive care admission. Indian J Crit Care Med Peer-Rev Off Publ Indian Soc Crit Care Med. 2014;18:497-502.

9. Zhao D, Zhang Y, Yin Z, Zhao J, Yang D, Zhou Q. Clinical predictors of multiple organ dysfunction syndromes in pediatric patients with scrub typhus. J Trop Pediatr. 2017;63:167-73.

10. Giri PP, Roy J, Saha A. Scrub typhus - a major cause of pediatric intensive care admission and multiple organ dysfunction syndrome: a single-center experience from India. Indian J Crit Care Med Peer-Rev Off Publ Indian Soc Crit Care Med. 2018:22:107-10.

11. Ganesh R, Suresh N, Pratyusha LL, Janakiraman L, Manickam M, Andal A. Clinical profile and outcome of children with scrub typhus from Chennai. South India. Eur J Pediatr. 2018;177:887-90.

12. Castillo L. High elevated ferritin levels and the diagnosis of $H \mathrm{LH} / \mathrm{Sepsis} / \mathrm{SIRS} /$ MODS/MAS. Pediatr Blood Cancer. 2008;51:710 author reply 710-711.

13. Garcia PCR, Longhi F, Branco RG, Piva JP, Lacks D, Tasker RC. Ferritin levels in children with severe sepsis and septic shock. Acta Paediatr Oslo Nor. 2007:96:1829-31.

14. Horvat CM, Bell J, Kantawala S, Au AK, Clark RSB, Carcillo JA. C-reactive protein and ferritin are associated with organ dysfunction and mortality in hospitalized children. Clin Pediatr (Phila). 2019;58:752-60.

15. Demirkol D, Yildizdas D, Bayrakci B, Karapinar B, Kendirli T, Koroglu TF, et al. Hyperferritinemia in the critically ill child with secondary hemophagocytic lymphohistiocytosis/sepsis/multiple organ dysfunction syndrome/ macrophage activation syndrome: what is the treatment? Crit Care Lond Engl. 2012;16:R52.

16. Williams V, Menon N, Bhatia P, Biswal M, Sreedharanunni S, Rawat A, et al. Serum ferritin predicts neither organ dysfunction nor mortality in pediatric sepsis due to tropical infections. Front. Pediatr. 2020;8:607673.

17. Khwaja A. KDIGO clinical practice guidelines for acute kidney injury. Nephron Clin Pract. 2012;120:c179-84. https://doi.org/10.1159/000339789.

18. Henter J-I, Horne A, Aricó M, Egeler RM, Filipovich AH, Imashuku S, et al. $\mathrm{HLH}-2004$ : diagnostic and therapeutic guidelines for hemophagocytic lymphohistiocytosis. Pediatr Blood Cancer. 2007:48:124-31.

19. Leteurtre S, Duhamel A, Salleron J, Grandbastien B, Lacroix J, Leclerc F, et al. PELOD-2: an update of the pediatric logistic organ dysfunction score. Crit Care Med. 2013;41:1761-73.

20. Gaies MG, Gurney JG, Yen AH, Napoli ML, Gajarski RJ, Ohye RG, et al. Vasoactive-inotropic score as a predictor of morbidity and mortality in infants after cardiopulmonary bypass. Pediatr Crit Care Med J Soc Crit Care Med World Fed Pediatr Intensive Crit Care Soc. 2010;11:234-8. 
21. Varghese GM, Janardhanan J, Trowbridge P, Peter JV, Prakash JAJ, Sathyendra S, et al. Scrub typhus in South India: clinical and laboratory manifestations, genetic variability, and outcome. Int J Infect Dis IJID Off Publ Int Soc Infect Dis. 2013;17:e981-7.

22. Jacobs A, Worwood M. Ferritin in serum. Clinical and biochemical implications. N Engl J Med. 1975;292:951-6.

23. Carcillo JA, Simon DW, Podd BS. How we manage hyperferritinemic sepsis related MODS/macrophage activation syndrome/secondary HLH. Pediatr Crit Care Med I Soc Crit Care Med World Fed Pediatr Intensive Crit Care Soc. 2015;16:598-600.

24. Wang W, Knovich MA, Coffman LG, Torti FM, Torti SV. Serum ferritin: past, present and future. Biochim Biophys Acta. 1800;2010:760-9.

25. Ruddell RG, Hoang-Le D, Barwood JM, Rutherford PS, Piva TJ, Watters D et al. Ferritin functions as a proinflammatory cytokine via iron-independent protein kinase C zeta/nuclear factor kappaB-regulated signaling in rat hepatic stellate cells. Hepatol Baltim Md. 2009;49:887-900.

26. Li R, Luo C, Mines M, Zhang J, Fan G-H. Chemokine CXCL12 induces binding of ferritin heavy chain to the chemokine receptor CXCR4, alters CXCR4 signaling, and induces phosphorylation and nuclear translocation of ferritin heavy chain. J Biol Chem. 2006;281:37616-27.

27. Bennett TD, Hayward KN, RWD F, Ringold S, Wallace CA, Brogan TV. Very high serum ferritin levels are associated with increased mortality and critical care in pediatric patients. Pediatr Crit Care Med J Soc Crit Care Med World Fed Pediatr Intensive Crit Care Soc. 2011;12:e233-6.

28. Briggs HL, Pul N, Seshadri R, Wilson MJ, Tersteeg C, Russell-Lodrigue KE, et al. Limited role for iron regulation in Coxiella burnetii pathogenesis. Infect Immun. 2008;76:2189-201.

29. Mertens K, Samuel JE. Defense mechanisms against oxidative stress in Coxiella burnetii: adaptation to a unique intracellular niche. Adv Exp Med Biol. 2012;984:39-63.

30. Ellison DW, Clark TR, Sturdevant DE, Virtaneva K, Hackstadt T. Limited transcriptional responses of Rickettsia rickettsii exposed to environmental stimuli. PloS One. 2009:4:e5612.

31. Tantibhedhyangkul W, Prachason T, Waywa D, El Filali A, Ghigo E, Thongnoppakhun $W$, et al. Orientia tsutsugamushi stimulates an original gene expression program in monocytes: relationship with gene expression in patients with scrub typhus. PLoS Negl Trop Dis. 2011;5:e1028.

\section{Publisher's Note}

Springer Nature remains neutral with regard to jurisdictional claims in published maps and institutional affiliations.

Ready to submit your research? Choose BMC and benefit from:

- fast, convenient online submission

- thorough peer review by experienced researchers in your field

- rapid publication on acceptance

- support for research data, including large and complex data types

- gold Open Access which fosters wider collaboration and increased citations

- maximum visibility for your research: over $100 \mathrm{M}$ website views per year

At $\mathrm{BMC}$, research is always in progress.

Learn more biomedcentral.com/submissions 